\title{
Discussion: Index and strength properties of clay-gravel mixtures
}

Benjamin S. Kyambadde MSc, PhD

Division of Civil Engineering, University of Brighton, UK

Kevin J. L. Stone PhD, CEng, MICE

Division of Civil Engineering, University of Brighton, UK
Graham Edward Barnes MSc, CEng, FICE, CGCol, FGS

Geotechnical consultant, Graham Barnes Consultancy, Manchester, UK

\section{Contribution by G. E. Barnes}

The authors have conducted some interesting research on the influence of gravel on the undrained shear strength and the index properties of a clay soil using cone penetration tests (Kyambadde and Stone, 2012). The authors acknowledge that there remains a requirement to develop the test procedure further to optimise sample preparation and data extrapolation. Concerning the latter, close inspection of the authors' Figures 4(a)-4(d) shows that the relationships between penetration load $F$ and penetration depth squared $d^{2}$ are not linear, with some curving upwards giving lower penetration depths when extrapolated to the $8 \mathrm{~kg}$ penetration load and some curving downwards giving higher penetration depths. Extrapolation using linear regression will then lead to erroneous points plotted on the authors' Figure 5.

A further series of linear extrapolations on the authors' Figure 5 to their theoretically derived penetration depth of $11.55 \mathrm{~mm}$ at a plastic limit value based on the strength ratio concept gives more room for error, as the nearest penetration depths on their Figure 5 are between 25 and $40 \mathrm{~mm}$. This is caused by the difficulties of sample preparation with stiffer soils at low moisture contents approaching the plastic limit.

The authors report that the undrained shear strengths of the claygravel mixtures appear to be unaffected by the presence of the gravel particles for gravel contents less than $45 \%$. This would mean that the undrained shear strength is determined by the clay phase or matrix and its moisture content $w_{\mathrm{C}}$ and the gravel acts only as a filler. Using the authors' Equation 5 there are three tests in Figures 4(a), 4(b) and 4(c) with very similar clay matrix moisture contents $w_{\mathrm{C}}$ of $27 \cdot 2$ and $27 \cdot 3 \%$ but with different gravel contents of 0,15 and $30 \%$. The authors' relationships of penetration load $F$ against penetration depth squared $d^{2}$ for these three tests, from Figures 4(a), 4(b) and 4(c), are plotted in Figure 10. This shows that gravel contents less than $45 \%$ do have an effect on the undrained shear strength if it is determined by the cone test and the authors' Equation 10. Decreasing penetration depths $d_{8}$ at the load of $8 \mathrm{~kg}$ are obtained with increasing gravel contents. Under the same penetration load $F$, smaller penetrations are obtained with the gravel contents of 15 and $30 \%$ compared with the clay alone, and this can probably be attributed to the gravel particles obstructing penetration of the cone.

The authors acknowledge that greater variation in penetration depths can be obtained with the fall-cone test on clay-gravel mixtures by introducing an additional set of three drops if the range of penetrations exceeds the BS 1377-2:1990 requirements (BSI, 1990).

The authors agree with previous researchers (Kumar, 1996; Kumar and Muir Wood, 1999; Muir Wood and Kumar, 2000) that the clay phase or matrix controls the liquid limit behaviour of the mixtures for clay contents above about $35 \%$ with the coarse particles (sand, gravel) making no contribution. This behaviour would comply with the relationship referred to as the 'linear law of mixtures' (Sivapullaiah and Sridharan, 1985) which is represented by the authors' Equation 5 and which gives a straight line passing through the origin and the liquid limit value at the clay content of $100 \%$ on the authors' Figure 7 . The authors' data for the liquid limits of the clay-gravel mixtures from their Figure 7 are plotted in Figure 11 and follow this linear law to the gravel content of about $45 \%$, as the authors report. With higher gravel contents the liquid limit values deviate from the linear law owing to the interference between the gravel particles.

There is no reason why the plastic limit values should not follow the linear law of mixtures, although with the lower moisture contents at this limit the plastic limit values would deviate from the linear law at lower gravel contents as there will be less claywater matrix between the gravel particles than at the liquid limit. The authors' plastic limit values $\mathrm{PL}_{100 \mathrm{M}}$, derived from their cone tests and the strength ratio concept, deviate from the linear law at even the lowest gravel content tested of $15 \%$, as shown in Figure 11. The authors' $\mathrm{PL}_{100 \mathrm{M}}$ values, extrapolated from their Figure 5, are overestimated because the cone penetration depths, $d$, are underestimated owing to the presence of the gravel, as illustrated in Figure 10.

The discusser considers that there are important objections to applying the results of cone tests to determine the undrained shear strength of a clay soil at low moisture contents and those containing gravel particles.

\section{Authors' reply}

The authors wish to thank the discusser for the interest shown in this paper and for raising some very interesting issues, which they have attempted to address as follows.

As astutely observed by the discusser there is some deviation from linearity in some of the penetration force $(F)$ plotted against 


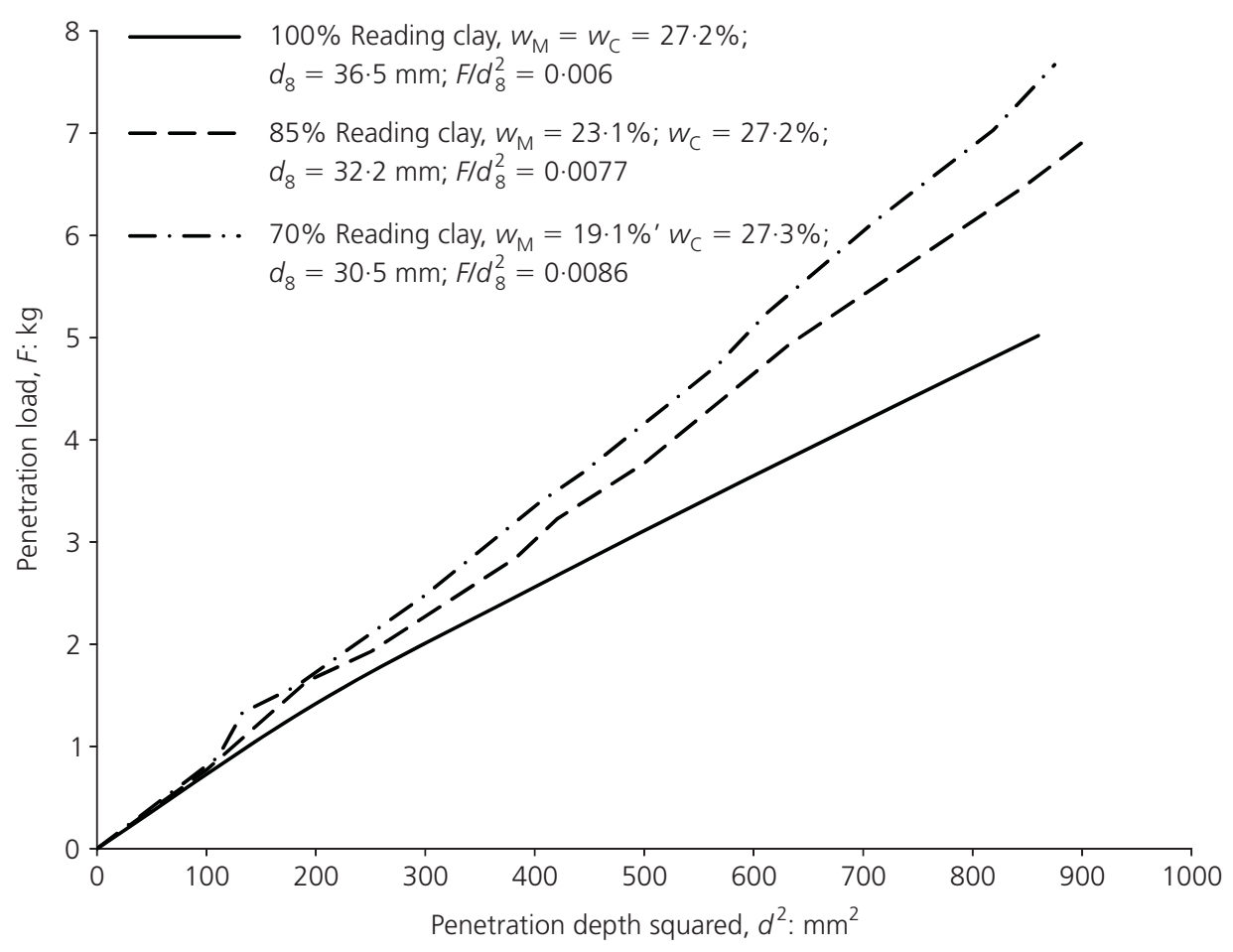

Figure 10. The effect of small gravel contents on cone test results

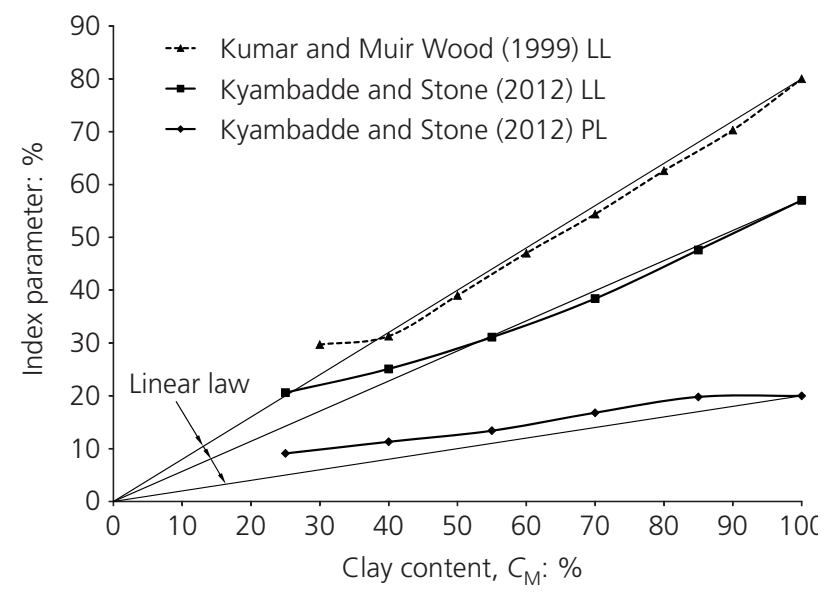

Figure 11. The linear law of mixtures

penetration depth squared $\left(d^{2}\right)$ relationships shown in Figures 4(a)-4(d), perhaps most notably for the $100 \%$ Reading clay plot at $27 \cdot 2 \%$ moisture content. In their analysis of the data, the authors also applied second-order polynomial fits to plots of $F$ against $d$ for comparison with the linear extrapolation of the $F$ against $d^{2}$ plots. This is illustrated in Figures 12(a) and 12(b) for the $100 \%$ clay tests. The penetration depths at a penetration force of $8 \mathrm{~kg}$ obtained from the quadratic or linear extrapolations are within $1 \mathrm{~mm}(+/-0.5 \mathrm{~mm})$. Also shown on the plots are the regression coefficients which indicate that either approach is a satisfactory interpretation of the data. The authors' intention in presenting an interpretation based on the $F$ against $d^{2}$ plots was to keep the interpretation of the data simple in accordance with an index test philosophy. It is also noted that the use of a $d^{2}$ axis will amplify the effect of the resolution capability of the displacement measurement. So the authors do not attach any significance to the deviations observed in some of the $F$ against $d^{2}$ plots, which are considered to lie within the tolerance of the experimental procedures and testing equipment. Furthermore, the linear relationship between $F$ and $d^{2}$ is considered to be consistent and robust and to hold over a large range of soil plasticity (Kyambadde, 2010).

The discusser is correct in that it is difficult to prepare test samples at low moisture contents, and there is a tendency to work with moisture contents that yield higher penetration depths than those associated with the theoretical value of $11.55 \mathrm{~mm}$ used here to define the $\mathrm{PL}_{100}$. It should be noted that if the range of moisture contents (and thus penetration depths) is relatively large then the authors would recommend a power law fit to the data rather than a linear fit. However, whichever relationship is used in the extrapolation to obtain a $\mathrm{PL}_{100}$ value has little influence on the result, since the penetration depth plotted against moisture content curve is relatively flat at low moisture contents. In Figure 9 both extrapolation approaches have been used and the difference in the $\mathrm{PL}_{100}$ values obtained is negligible.

The discusser has presented $F$ against $d^{2}$ plots for three tests with 


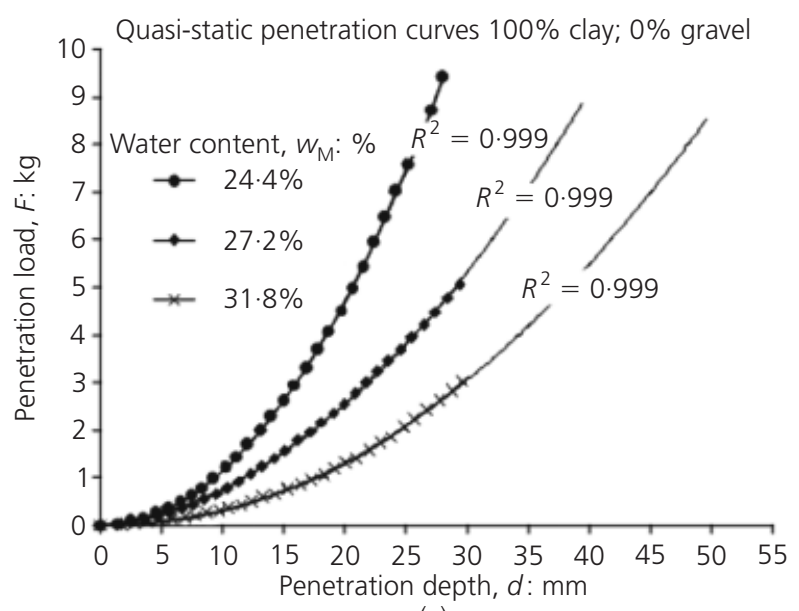

(a)

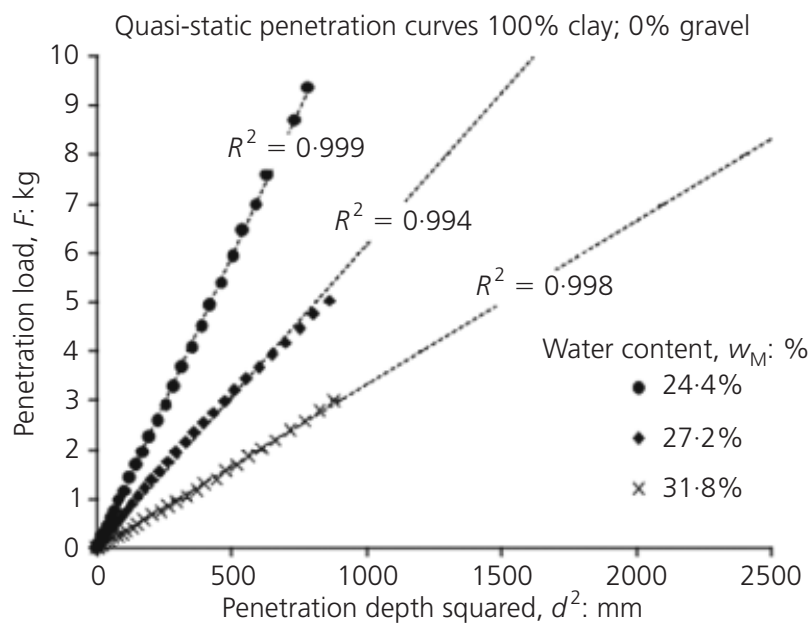

(b)

Figure 12. (a) Penetration force plotted against penetration depth; (b) penetration force plotted against penetration depth squared

similar clay moisture contents in Figure 10. These data are essentially presented in Table 2 and Figure 3 of the paper where the undrained strength of the mixtures, as derived with a cone factor of 0.53 , was plotted against the clay moisture content (please note the typographical error in Table 2 where column 2 should read 'Clay moisture content: \%'). These data were combined with the undrained strengths derived from the fall-cone tests to form a complete undrained strength against clay moisture content relationship over the range of moisture contents tested. The authors consider that this illustrates the consistency of behaviour being dependent on the clay phase of the mixtures up to about $45 \%$ gravel content. Further evidence that the clay phase controls the strength of the mixture can be inferred from Figure 8, which shows the liquid limit (LL) and $\mathrm{PL}_{100}$ values of the mixtures normalised to the clay content. Since both the LL and $\mathrm{PL}_{100}$ values are associated with unique strengths and the normalised indices up to about $55 \%$ clay content are relatively constant in Figure 8, it is implicit that the undrained strength of the mixture is not significantly influenced by the gravel over this range of clay content. So the authors are of the opinion that the undrained strength of the mixture is primarily controlled by the clay phase within the observance of the linear law of mixtures, until the granular volume fraction becomes significantly large for the gravel particles to interact with each other (hence adding a frictional component to the strength).

The authors agree with the discusser that the plastic limit would adhere to the linear law of mixtures and believe that this is illustrated quite well in Figure 7 and the discusser's Figure 11. However, the authors would choose not to rely on the data point for $100 \%$ clay for fixing the slope of the linear relationship, but rather to consider the linear portion of the data points (as indicated in Figure 13). Inspection of the data presented in Figure 5 shows that, owing to the scatter in the three data points presented for the $100 \%$ clay, a range of values for the $\mathrm{PL}_{100}$ can be obtained. They are thus of the opinion that the discusser has been somewhat misled by the single data point for the $100 \%$ clay in fixing the slope of the linear law of mixtures in Figure 11.

The authors also note that the discusser has labelled the indices as LL and PL in Figure 11, whereas the figure implies that the data refer to the mixtures. The authors must emphasise that the data labelled PL should be labelled $\mathrm{PL}_{100}$ so as to avoid confusion with the conventional plastic limit defined through the thread rolling test.

In conclusion, the authors thank the discusser for these very valuable comments and are pleased that the study was found to be interesting. The main objective of the paper was to present an alternative index testing approach that can eliminate the requirement for separating the coarse and fine fractions of soil mixtures in determining the soil 'plasticity'. The 'plasticity' is defined

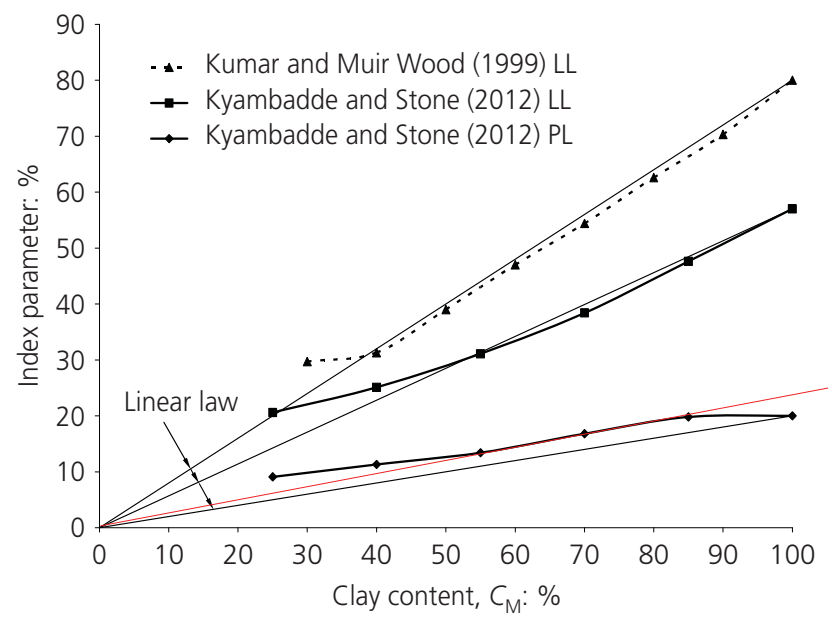

Figure 13. Adaptation of the discusser's Figure 11 
through upper and lower moisture contents associated with a strength test. The upper moisture content index remains the conventional liquid limit (as measured in a fall-cone apparatus). For the lower moisture content, an alternative 'plastic' limit ( $\mathrm{PL}_{100}$ in this case) is used, which is based on a quasi-static cone penetration test as opposed to the conventional thread rolling test. The authors believe that the quasi-static cone penetration approach offers some consistency in the evaluation of 'plasticity' indices, and that these indices can be interpreted usefully in terms of the strength range of the soil for engineering purposes.

So in the context of this study, and in contrast to the view of the discusser, the authors are of the opinion that cone penetration testing offers a useful method for estimating the undrained strength of fine-grained soils and fine-coarse soil mixtures over a large range of moisture contents within their plastic range. Furthermore, such tests can form the basis for simple and reliable estimations of soil 'plasticity'. It is emphasised that this approach, essentially based on that outlined by Wood and Wroth (1978), should be considered as providing additional index parameters which are not necessarily equivalent to the plasticity index conventionally defined through the thread rolling plastic limit and fall-cone liquid limit tests.

\section{REFERENCES}

BSI (1990) BS 1377: Part 2: Methods of test for soils for civil engineering purposes. BSI, Milton Keynes, UK.

Kumar GV (1996) Some Aspects of the Mechanical Behaviour of Mixtures of Kaolin and Coarse Sand. $\mathrm{PhD}$ thesis, University of Glasgow, UK.

Kumar GV and Muir Wood D (1999) Fall cone and compression tests on clay-gravel mixtures. Géotechnique 49(6): 727-739.

Kyambadde BS (2010) Strength and Consistency of Limits from Quasi-Static Cone Tests. PhD thesis, University of Brighton, Brighton, UK.

Kyambadde BS and Stone KJL (2012) Index and strength properties of clay-gravel mixtures. Proceedings of the Institution of Civil Engineers - Geotechnical Engineering 165(1): 13-21, http://dx.doi.org/10.1680/geng.2012.165.1.13.

Muir Wood D and Kumar GV (2000) Experimental observations of behaviour of heterogeneous soils. Mechanics of CohesiveFrictional Materials 5(5): 373-398.

Sivapullaiah PV and Sridharan A (1985) Liquid limit of soil mixtures. ASTM Geotechnical Testing Journal 8(3): 111-116.

Wood DM and Wroth CP (1978) The use of the cone penetrometer to determine plastic limit of soils. Ground Engineering 11(3): 37. 